\title{
Dissociating the Reinforcing and Discriminative Roles of a Warning Signal in a Free-Operant Avoidance Situation
}

Bobby E. Phillips

West Virginia University

Follow this and additional works at: https://researchrepository.wvu.edu/etd

\section{Recommended Citation}

Phillips, Bobby E., "Dissociating the Reinforcing and Discriminative Roles of a Warning Signal in a FreeOperant Avoidance Situation" (2010). Graduate Theses, Dissertations, and Problem Reports. 3063. https://researchrepository.wvu.edu/etd/3063

This Thesis is protected by copyright and/or related rights. It has been brought to you by the The Research Repository @ WVU with permission from the rights-holder(s). You are free to use this Thesis in any way that is permitted by the copyright and related rights legislation that applies to your use. For other uses you must obtain permission from the rights-holder(s) directly, unless additional rights are indicated by a Creative Commons license in the record and/ or on the work itself. This Thesis has been accepted for inclusion in WVU Graduate Theses, Dissertations, and Problem Reports collection by an authorized administrator of The Research Repository @ WVU. For more information, please contact researchrepository@mail.wvu.edu. 


\title{
Dissociating the Reinforcing and Discriminative \\ Roles of a Warning Signal in a Free-Operant Avoidance Situation
}

Bobby E. Phillips

Thesis submitted to the Eberly College of Arts \& Sciences at West Virginia University

in partial fulfillment of the requirements

for the degree of

Master of Science

in

Psychology

\author{
Michael Perone, Ph.D., Chair \\ Karen G. Anderson, Ph.D. \\ Tracy L. Morris, Ph. D. \\ Department of Psychology
}

Morgantown, West Virginia

2010

Keywords: avoidance; negative reinforcement; warning signal; conditioned punishment 


\begin{abstract}
Dissociating the Reinforcing and Discriminative

Roles of a Warning Signal in a Free-Operant Avoidance Situation
\end{abstract}

Bobby E. Phillips

The two-factor theory of avoidance behavior predicts that a warning signal that precedes shock will have an aversive function, and if this is true then presenting a warning signal contingent upon a response should punish that response. In the present study, rats responded in a twocomponent multiple schedule of free-operant shock avoidance. Both components used a response-shock (RS) interval of $30 \mathrm{~s}$, and a shock-shock (SS) interval of $5 \mathrm{~s}$. A distinct warning signal was presented in each component, and signals differed primarily in terms of their respective durations. In one component, the signal appeared $29 \mathrm{~s}$ before RS shocks, and in the other component the signal appeared $5 \mathrm{~s}$ before RS shocks. Following the establishment of stable baseline responding under this arrangement, a conditioned punishment phase was conducted. The 5-s signal was presented briefly ( $0.5 \mathrm{~s}$ ) following responses in the component with the 29-s signal. This had little effect on response rates and IRT distributions in the 29-s-Signal component for four of five rats. Relative to baseline, the fifth rat had lower overall response rates and fewer short IRTs in the 29-s-Signal component during conditioned punishment. When this fifth rat was introduced to a sham punishment condition, in which an arbitrary stimulus was presented for 0.5 $\mathrm{s}$ following responses in the 29-s-Signal component, response rates and IRT distributions in that component approximated baseline results. However, subsequent attempts to replicate baseline and sham punishment conditions with this rat were not successful. Taken together, presenting warning signals contingent upon a response did not suppress responding, as the two-factor theory would predict. 


\section{Acknowledgements}

I would like to thank Karen Anderson, Tracy Morris, and Michael Perone for serving on my thesis committee and for providing comments and questions that have shaped my considerations for future research.

I extend my special thanks to Mike for his advice and guidance throughout the course of this project. Without his reassurances, undoubtedly I would have given up the project as hopeless.

I also thank the members of Reformation Orthodox Presbyterian Church in Morgantown, West Virginia, for their encouragement over the last two years. They have been like my family away from my family, and the thought and interest which they showed for the progress of my thesis often lifted me out of those dark moods that are known among graduate students as “second-year blues.” 


\section{Table of Contents}

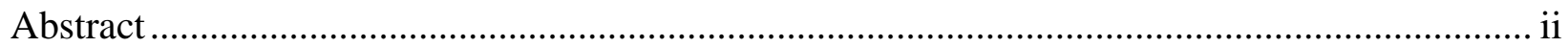

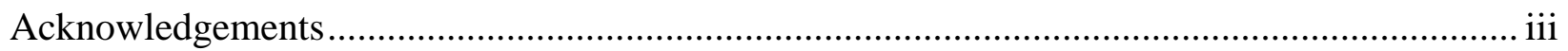

Table of Contents ........................................................................................................ iv

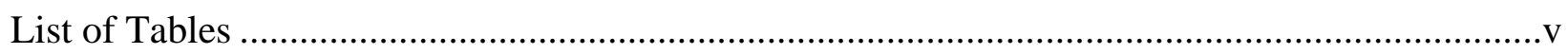

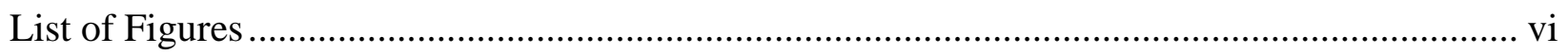

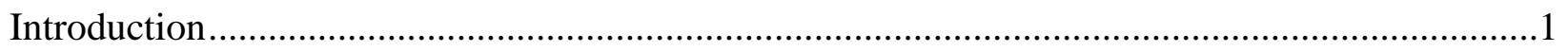

Statement of the Problem .................................................................................

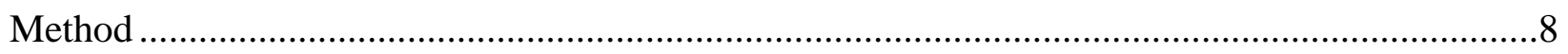

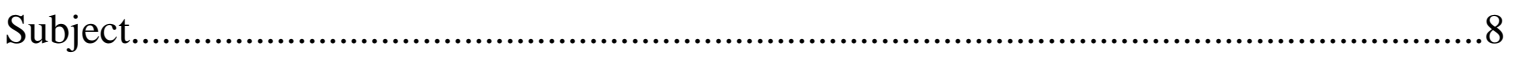

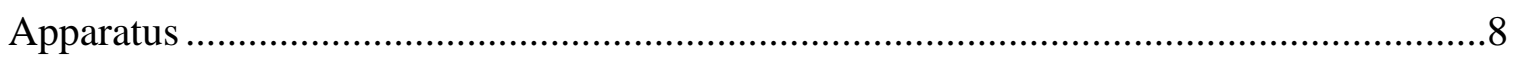

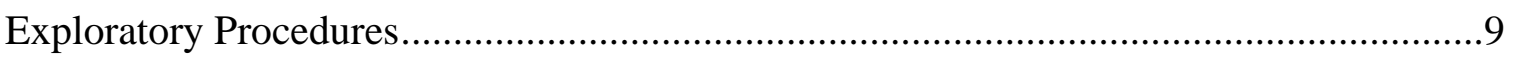

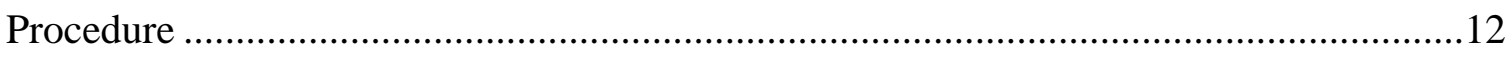

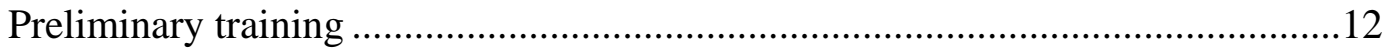

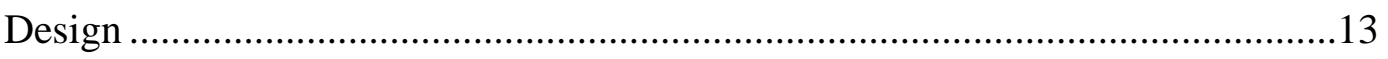

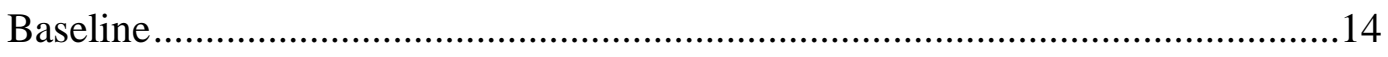

Conditioned punishment ..........................................................................14

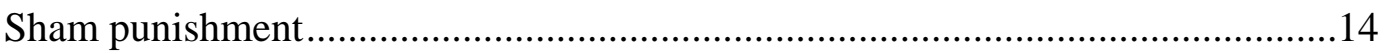

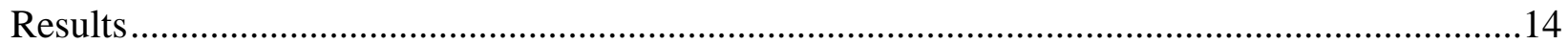

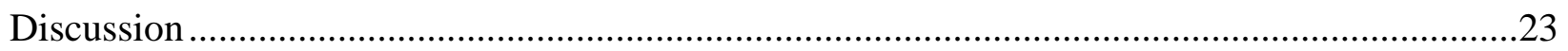

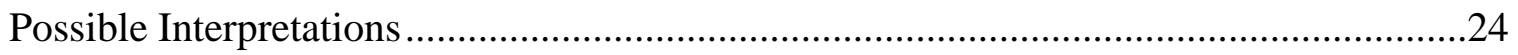

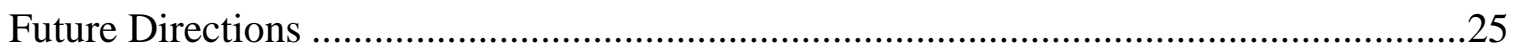

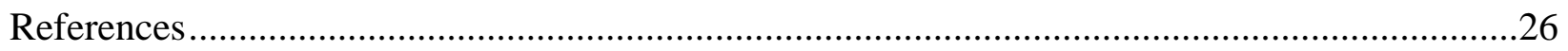




\section{List of Tables}

Table 1. Conditions in which each rat served, and number of sessions in each condition ...........13

Table 2. Percentage of RS shocks avoided in each condition ................................................15 


\section{List of Figures}

Figure 1. Frequency distributions of interresponse times in each component of the first two baseline conditions (left and middle columns), and of the average of those baselines (right column)

Figure 2. Mean response rates in each component of the multiple schedule, measured across the last 10 sessions of each condition 18

Figure 3. Rat C1's interresponse time distributions in several pairs of sequentially presented conditions. Data from the 29-s-Signal component of the multiple schedule appears in the left column, and data from the 5-s-Signal component appears in the right column

Figure 4. Rat C2's interresponse time distributions in several pairs of sequentially presented conditions. Data from the 29-s-Signal component of the multiple schedule appears in the left column, and data from the 5-s-Signal component appears in the right column

Figure 5. Rat C3's interresponse time distributions in several pairs of sequentially presented conditions. Data from the 29-s-Signal component of the multiple schedule appears in the left column, and data from the 5-s-Signal component appears in the right column

Figure 6. Rat C4's interresponse time distributions in several pairs of sequentially presented conditions. Data from the 29-s-Signal component of the multiple schedule appears in the left column, and data from the 5-s-Signal component appears in the right column

Figure 7. Rat C5's interresponse time distributions in several pairs of sequentially presented conditions. Data from the 29-s-Signal component of the multiple schedule appears in the left column, and data from the 5-s-Signal component appears in the right column 


\section{Introduction}

In an avoidance situation, the emission of a response prevents the occurrence of an aversive stimulus by either postponing it or deleting it. When maintained effectively, avoidance behavior is emitted in the absence of the aversive stimulus, and its emission extends that absence. The question, then, is why an organism would respond so as to move from one presently nonaversive situation to another. To appeal to future "expectations" on the part of the organism is to state paradoxically that an effect produces a cause. The conventional answer to this problem - the "two-factor" theory initially proposed by Mowrer $(1939,1947)$ and later modified by Schoenfeld (1950), Skinner (1953), Sidman (1953b), and Dinsmoor (1954)—has been to explain avoidance behavior as being the product of respondent conditioning and operant conditioning. These two processes are readily observed in the discrete-trial procedures that were commonly used in early studies on avoidance (e.g., Mowrer \& Lamoreaux, 1942). Typically, during one block of trials a subject is presented an arbitrary stimulus (i.e., a warning signal) such as a buzzer or a light that is followed shortly by a shock. During a second block of trials the subject is presented with the warning signal in each trial. If the subject emits a response that has been specified by the experimenter, the warning signal is removed and the trial ends without the delivery of shock. If the subject fails to respond, shock is delivered at the end of the trial. It is typical, in the second block of trials, for subjects eventually to acquire the response. Ostensibly, the warning signal acquires an aversive function through respondent conditioning in the first trial

block, and responding is negatively reinforced when it terminates the warning signal in the second block. These two processes can be generalized to any case where a warning signal reliably precedes shock (i.e., primary aversive stimulation). In such situations, behavior that avoids shock is construed to be escape from conditioned aversive stimuli.

In the discrete-trial studies mentioned above, subjects had only isolated opportunities to avoid a shock. Sidman (1953a, 1953b), however, introduced a procedure in which avoidance could be studied as a continuous stream of free-operant behavior. A brief electric foot-shock was presented to a rat at a regular interval (the shock-shock or SS interval) unless it pressed a response lever. Once a lever press occurred, the next shock was postponed according to a second interval (the response-shock or RS interval). If this RS interval elapsed without another leverpress response, a shock was presented and control of subsequent shocks reverted to the SS timer. However, if the rat responded before the end of the RS interval, the RS timer was reset and the 
cycle was repeated. Therefore, the rat could avoid all programmed shocks by responding before the RS interval elapsed. Failure to respond at all resulted in regular shocks according to the SS interval.

In Sidman’s (1953a, 1953b) initial research with shock-postponement schedules, the rats were not presented with an exteroceptive warning signal. That the rats acquired the avoidance response anyway did not pose an insurmountable challenge to the two-factor theory, however. An early defense of the two-factor theory came from Schoenfeld (1950; see also Dinsmoor, 1954), who argued that when a subject does not emit a response in an avoidance situation, this generates proprioceptive stimuli in the body that become paired with shock in the same way that an exteroceptive stimulus might. Because avoidance behavior terminates these stimuli, it is negatively reinforced.

Nevertheless, there were still questions to be answered about a warning signal's properties. Using cats and rats as subjects, Sidman (1955, Experiment 1) compared his “unsignaled” procedure to one in which a salient exteroceptive stimulus (either a flashing neon pilot light or an audible tone) was presented shortly (e.g. 5 s) before each scheduled shock. In both the unsignaled and signaled conditions, the RS and SS intervals were of equal duration (e.g. RS 20-s SS 20-s). In the signaled condition, if the subject responded before the warning signal's onset, then the RS timer was reset and both the signal and the shock were postponed. If the subject responded after the onset of the signal, then the RS timer was reset, the warning signal was terminated, and shock was postponed. Failure to respond terminated the signal, shocked the subject, and shifted control of subsequent shocks to the SS timer. The warning signal came on again prior to each scheduled SS shock. The general effect of introducing the signal was a decrease in subjects' mean response rates over several sessions. Whereas in the unsignaled condition responses were not concentrated in any particular part of the schedule, in the signaled condition the majority of responses occurred after the onset of the warning signal. In other words, the subjects tended to wait until the warning signal appeared before responding.

The puzzle that arose from Sidman's (1955) findings is why an organism would allow the warning signal to appear and only then escape from it (Herrnstein, 1969; Hineline, 1977; Hineline, 1981). If the signal acquires an aversive property by virtue of its correlation with shock, then one might expect the subject to respond earlier in the RS and SS intervals so as to avoid the warning signal. To the contrary, Sidman’s (1955) animals actually made fewer 
responses during the time that preceded the warning signal's onset. At first blush, this seemed to be a major challenge to the two-factor explanation. Dinsmoor (2001), however, had a simple answer to that challenge: "Such [presignal] responses do not produce a change in the exteroceptive stimuli from ones that are positively correlated (warning) to ones that are negatively correlated (safety) with the shock, as demanded by two-factor theory” (p. 325). Yet despite such retorts, Sidman's (1955) results gave rise to doubts about the two-factor account, and increasingly, some critics came to view the notion that avoidance was mediated by a respondent conditioning process as “excess baggage” (Sidman, 2001). Instead, avoidance was construed to be a basic process that was directly attributable to contingent decreases in the molar frequency or severity of shock (Herrnstein, 1969; Herrnstein \& Hineline, 1966; Hineline, 1981; Sidman, 1966).

This "shock-density-reduction" theory (sometimes called "one-factor" theory because it relies solely on negative reinforcement as an explanatory mechanism) emphasized the discriminative function of the warning signal (Hineline, 1977, 1981; Sidman, 1955). It was recognized that responses late in the RS interval produced greater increments in the postponement of shock than did responses early in the interval, and the warning signal—which appeared just prior to shock-was necessarily correlated with a period during which responding would be maximally effective. Although it had been assumed by two-factor theorists that an organism tended to respond in the presence of the warning signal because those responses were negatively reinforced by termination of the signal (escape), it was equally possible that this pattern reflected the warning signal's discriminative role as a stimulus that was differentially correlated with a richer "schedule" of negative reinforcement.

An illustration of this discriminative role may be found in a signaled shock-postponement study conducted by Sidman and Boren (1957b; see also Sidman, 1957). In Experiment II of this study, an RS interval was divided into two time segments: one preceded onset of a neon pilot light which served as the warning signal (the response-light interval) and one followed the light's appearance but preceded shock (the light-shock interval). A response in the response-light interval (i.e., in the absence of the light) postponed both the light and the shock that followed. A response during the light-shock interval (i.e., in the presence of the light) only postponed shock and looped the timer back to the start of the light-shock interval. However, if there was no 
response in the light-shock interval and a shock occurred, the schedule reverted to the start of the response-light interval.

In both baseline and experimental conditions of Sidman and Boren's experiment, the response-light interval was $20 \mathrm{~s}$, and the light-shock interval was $10 \mathrm{~s}$ (adding up to a total RS interval of $30 \mathrm{~s}$ ). In the baseline condition, the occurrence of a shock terminated the warning signal, as described above. In the experimental condition, once the subject permitted the light to appear, it remained on for 5 min while the shock-postponement contingencies of the responselight and light-shock intervals were still in place. In baseline, response rates tended to be higher in the response-light interval than in the light-shock interval. When the light duration was fixed at $5 \mathrm{~min}$ in the experimental condition, response rates in the response-light interval were virtually unchanged for all the rats, but rates in the light-shock interval increased relative to baseline, to the point that they exceeded the rates in the response-light interval. In other words, the rats were less likely to respond in the baseline condition, when withholding a response could terminate the light, than in the experimental condition, in which the light terminated independent of responding. This was the case even though the contingency between light and shock had not been changed. Sidman and Boren (1957b) conceded that their results could be interpreted to mean that under some conditions a warning signal could be even more aversive than the shock it preceded, because response rates had been relatively low when enduring shock resulted in the termination of the warning signal. However, they argued that their data were better interpreted in light of a discriminative role of the warning signal. In baseline the warning signal's presence and absence identified two different intervals within the overall schedule and controlled responding accordingly. When the light's duration was made independent of responding, however, it was present in both intervals and could no longer bring responding under differential control. Although Sidman and Boren did not dismiss the light's role as a conditioned aversive stimulus, they recognized that its discriminative role had not received enough attention in the literature.

Yet Sidman and Boren's (1957b) study did not separate the warning signal's dual roles as an aversive and discriminative stimulus. Although the 5-min duration condition abolished the correlation between the light and the contingencies of the light-stimulus interval (discriminative function), it had also eliminated the contingency of terminating the light by enduring the shock (reinforcing function). Manipulating one function had necessarily changed the other. Indeed, it proves quite difficult to design a free-operant test that dissociates the two roles. For example, one 
might suggest that a solution would be to vary the duration of the warning signal and then measure the response latency from the time of the signal's onset. The two-factor theory would predict that a warning signal that precedes shock by a small amount of time would be more aversive than a signal that appears a long time before shock, and a subject would be expected to respond sooner to escape a more aversive stimulus. This is, as a matter of fact, what the literature reveals: Response latency from signal onset decreases as the signal is shortened (de Moraes \& Todorov, 1977; Hyman, 1969). This does not resolve the interpretive issue, however, because the evidence can just as well be construed in terms of a discriminative function. It is possible that subjects respond rapidly in the presence of a short warning signal because it is correlated with a greater increment in shock postponement.

Another study by Sidman and Boren (1957a, Experiment I) illustrates the problem more explicitly. Their experiment included two between-groups conditions: (a) avoidance discrimination and (b) "anxiety” discrimination. In Phase I, rats in both conditions were exposed to Sidman's (Sidman, 1953a, 1953b) unsignaled avoidance procedure. In Phase II, rats in the avoidance discrimination condition responded under a signaled shock-postponement schedule. The RS and SS timers were set at 20 s (RS 20-s SS 20-s), and a warning signal was presented $5 \mathrm{~s}$ before both RS and SS shocks. Responses before the warning signal's onset postponed both the signal and the shock, and responses after the signal's onset terminated the signal and postponed shock. If the subject allowed a shock to occur, the signal terminated and the SS timer controlled subsequent shocks until another response occurred. In the anxiety discrimination condition, RS and SS timers were set at $20 \mathrm{~s}$, and shocks terminated the warning signal. However, the signal was presented $4 \mathrm{~s}$ before RS and SS shocks, and in the signal's presence responding had no programmed consequences: Once the warning signal was presented, the shock that followed was unavoidable. After a shock, the warning signal terminated, and subsequent shocks were controlled by the SS timer, unless a response occurred. Thus, in anxiety discrimination, the only effective avoidance responses were those that were made in the absence of the warning signal.

Results in the avoidance discrimination condition replicated Sidman's (1955) earlier work: The rats responded primarily during the warning signal. The pattern of responding was different for rats in the anxiety discrimination condition. Relative to Phase I, three of four rats in Phase II initially showed greater response rates in the absence of the warning signal. Although responding subsequently decreased for these three subjects, their rates during the pre-signal 
interval were nevertheless proportionally higher than rates in the signal's presence, a trend which persisted until the end of Phase II. Moreover, responses in the anxiety discrimination condition were not concentrated in any particular portion of the $16 \mathrm{~s}$ before the warning signal's appearance. In other words, the rats' responses during the interval that preceded the signal showed the same sort of even temporal distribution that had been observed in Sidman's (1953a, 1953b) unsignaled shock-postponement schedule.

On the one hand, one might interpret Sidman and Boren’s (1957a) results in terms of the two-factor theory's prediction that a neutral stimulus correlated with a primary aversive stimulus would itself acquire an aversive function. In avoidance discrimination, termination of the warning signal reinforced avoidance responses in its presence. When the signal's termination was no longer available in anxiety discrimination, rats avoided the signal itself, just as they might avoid shock in an unsignaled shock-postponement procedure On the other hand, one might argue for the warning signal's discriminative function. In Phase II of anxiety discrimination, the signal delineated a situation in which responding was ineffective. Negative reinforcement was available only in the absence of the warning signal. Thus, Sidman and Boren's (1957a) procedure could not distinguish the warning signal's reinforcing function from its discriminative function. A different procedure was and still is needed.

The goal of the present study was to separate the negative reinforcing function of a warning signal from its discriminative function. This was planned to be accomplished in two phases. In the first phase, the study would use resistance to extinction to measure the strength of avoidance responding as a function of the warning signal's duration. Both the two-factor theory, which emphasizes the signal's negative reinforcing role, and the shock-density-reduction theory, which emphasizes the signal's discriminative role, would predict a greater resistance to extinction when the warning signal's duration is relatively short. A resistance-to-extinction procedure was intended to provide a test of both theories and to determine which signal durations would be appropriate for the second phase of testing: conditioned punishment. In the second phase, brief exposure to different warning signals would be presented as a direct consequence of behavior. If the signals differed in aversiveness (two-factor theory), then they also should have differed in terms of suppressing behavior. If the signals differed solely in terms of a discriminative function (shock-density-reduction theory), then they should not have differed in terms of suppression. However, problems emerged in the study during the early stages of 
training, and the first phase was abandoned. The second phase, conditioned punishment, became the focus of the experiment.

\section{Statement of the Problem}

In Sidman’s (1953a, 1953b) free-operant shock-postponement procedure, brief shocks are presented periodically according to an SS timer unless the subject emits a response specified by the experimenter. Once such a response is made, control of the next scheduled shock is transferred to an RS timer. Additional responses during the RS interval reset this timer, whereas failure to respond before the RS interval has elapsed results in a shock and a regress of control to the SS timer.

In the signaled version of this procedure, a salient exteroceptive stimulus (typically a light or tone) precedes shocks by a fixed amount of time (Sidman, 1955). A response not only postpones the shock, but also terminates the warning signal when it is on, and postpones its onset when it is off. Under this schedule, subjects tend to pause until the onset of the warning signal before emitting a response, regardless of the signal's duration (Hyman, 1969; Sidman, 1955; Ulrich, Azrin, \& Holz, 1964). This observation can be interpreted in at least two ways. First, it could be argued that the signal functions as a conditioned negative reinforcer; the subject responds to escape from the warning signal because it has become an aversive stimulus through its association with the shock (Dinsmoor, 1977, 2001). Second, subjects may respond in the presence of the signal because it functions as a discriminative stimulus that delineates a period when shocks may be postponed for the maximum amount of time (Hineline, 1977, 1981; Sidman, 1955).

In most procedures these two roles of the warning signal-reinforcing and discriminative-are confounded (Hineline, 1977, 1981). The present study was designed to dissociate those roles in a free-operant context. Rats responded in two components of a multiple shock-postponement schedule. The RS and SS intervals of the components were identical. The components differed in terms of the nature of the warning signal (white noise in one component, a 32-Hz click in the other) and its duration (29 s versus $5 \mathrm{~s}$ ). After stable baseline responding was established in both components, a conditioned punishment condition followed: The warning signal from the 5-s Signal component was presented briefly (0.5 s) following each response in the 29-s Signal component, while the 5-s Signal component itself was not changed. If introducing the 5-s signal suppressed responding in the 29-s Signal component, it might be 
inferred that the 5-s signal had acquired a clear aversive function due to its association with immanent shock. To confirm this interpretation, one of the rats was subjected to a sham punishment condition: Instead of the 5-s signal, an arbitrary stimulus (tone) which had not been correlated with shock would be presented following each response in the 29-s Signal component.

\section{Method}

\section{Subjects}

Nine male Sprague-Dawley rats were housed in individual cages under a 12:12 hour reversed light/dark cycle with free access to food and water. Seven rats served during a series of preliminary procedures that were conducted to establish baseline responding. Of these, three (C1, C2, and C3) also served in the main study, along with two other rats (C4 and C5). All rats were experimentally naïve prior to these procedures with the exception of C4, which had previously served in several experiments, all involving food reinforcement, conducted in an undergraduate laboratory class. Rats C1, C2, C3, and C5 were about 60 days old at the start of the study, and C4 was about 12 months old at the start.

\section{Apparatus}

Two custom-built operant chambers and two commercial chambers (Lehigh Valley Electronics) were used. The interiors were approximately $30 \mathrm{~cm}$ long, $21 \mathrm{~cm}$ high, and $19 \mathrm{~cm}$ deep. In each commercial chamber, the side walls and ceiling were constructed of Plexiglas, and the end walls of stainless steel. The floor consisted of stainless steel rods, $0.5 \mathrm{~cm}$ in diameter, spaced $1.9 \mathrm{~cm}$ apart, center to center. Illumination was provided by a 28-V houselight (No. 1820) mounted behind a sheet of white paper on a side wall. Two levers are centered $10 \mathrm{~cm}$ apart on the front wall, $9 \mathrm{~cm}$ above the grid floor. In the custom-built chambers, the rear wall, ceiling, and one side wall were constructed of clear Plexiglas, the other side wall of stainless steel, and the front wall of aluminum. The levers were $8.5 \mathrm{~cm}$ apart, $9.6 \mathrm{~cm}$ above the floor, and the floor rods were spaced $1.7 \mathrm{~cm}$ apart. General illumination was provided by a houselight at the top of the front wall. In all four chambers, the left lever (BRS/LVE, RRL-015) was retractable and the right was fixed in place. During preliminary procedures both levers were inserted for some sessions, while in others only the right lever was inserted. In the main procedure, only the right lever was inserted. The levers required a force of approximately $0.3 \mathrm{~N}$ to operate. Shock generators and scramblers (Med Associates) could deliver scrambled 1-mA shocks lasting $0.5 \mathrm{~s}$ through the grid floors (but not the levers or walls). Each chamber was enclosed in a sound-attenuating box 
equipped with a fan for ventilation and a speaker for white noise, tones, and click sounds. Clicks also could be produced via a $24 \mathrm{~V}$ DC relay mounted behind the front wall. Throughout the experiment, activation of the houselight signaled the onset of the session, and this event was terminated at the end of the session, as well as during intervals between multiple-schedule components. Control and recording operations were accomplished with microcomputers.

\section{Exploratory Procedures}

The procedure was originally designed to include a test in which the effects of avoidance condition with warning signals of various durations on response strength would be compared under extinction conditions. Of interest was whether short-duration signals would generate more persistent responding than long-duration signals. Rats were to respond under a two-component multiple schedule with a free-operant avoidance schedule in both components. Each component schedule was to consist of a 30-s RS interval with a 5-s SS interval, and each component would be assigned to a separate lever. During each component, the cue light positioned over that component's lever would be illuminated. The components also were to differ in terms of the nature and duration of an auditory warning signal presented during the RS interval. The two warning signals would be white noise and a 1000-Hz tone, and the components to which these were assigned were counter-balanced across rats. In the Constant component the warning signal's duration was to be fixed at 29 s. In the other component (the Variable component), the warning signal was to be varied from 5 s to 29 s across several conditions. Sessions would consist of 7 presentations of each component, in strict alternation. Components would last 10 min and would be separated by 30-s intercomponent intervals. Each condition of the experiment would consist of a baseline phase, followed by an extinction test during which all scheduled shocks would be omitted.

A second phase, conditioned punishment tests, was planned to follow the extinction test phase. The second phase would begin with a replication of the baseline condition from the extinction test that produced the greatest differences in resistance to extinction. Once this baseline was replicated, a conditioned punishment condition would follow. In the punishment tests, the warning signal from the Variable component would be presented briefly (for $0.5 \mathrm{~s}$ ) following every response in the Constant component. The Variable component would remain unaltered. 
Problems emerged with the extinction-test procedure as it was executed. The first condition of the extinction tests used a multiple schedule of shock avoidance in which the warning signal's duration was $29 \mathrm{~s}$ in both components. Because all other schedule conditions were equal across components-except the nature of the warning signal (i.e., white noise or tone), which was presumed to be inconsequential-proficiency of avoidance (defined as mean percentage of RS shocks avoided) also should have been equal across components. Of the 4 rats that were used during the first attempt at extinction tests, all of them avoided shock with high proficiency when each component was presented in isolation. However, once the components were alternated in the context of a multiple schedule, proficiency was consistently much higher in one component for 3 of 4 rats.

A discrimination analysis was conducted to determine if the use of a separate lever for each component was interfering with avoidance proficiency. Lever responses for one component were measured during the other component and were counted as errors of discrimination. The analysis showed a low error rate in both components for all rats. Therefore, low proficiency at avoiding RS shocks could not be explained by a failure of lever pressing to come under the control of each component's discriminative stimuli (cue light and warning signal). Nevertheless, it was still possible that the use of two levers was interfering with avoidance proficiency, so as a precaution the procedure was changed so that both components were assigned to a single lever and cue light. This resulted in marginal improvements in avoidance proficiency for 2 of the 4 rats, but the disparities remained in proficiency between the two components.

The rats' avoidance proficiencies were then analyzed on a component-by-component basis for each session. Generally, within any given session, subjects improved their performance with each successive presentation of a component. From these analyses, it was hypothesized that proficiency in both components could be made more equal if sessions were lengthened to give subjects more extensive exposure to the contingencies. Instead of 7 presentations of each component in each session, the rats were given 14. In terms of time, sessions were now approximately 5 hrs long and were conducted every other day. Following this manipulation, one rat's performance deteriorated, and the proficiencies of the other 3 rats showed no change.

Upon closer inspection, one variable was identified to be the only factor consistently correlated with differences in performance across the two components: the type of stimulus used as a warning signal. In every subject, performance was worse in the component that contained a 
$1000-\mathrm{Hz}$ tone as the warning stimulus. Previous research (e.g., Frieman, Warner, \& Riccio, 1970) has succeeded in establishing $1000-\mathrm{Hz}$ tones as warning signals for rats, so it was unlikely that there was anything intrinsic to the nature of tones that would cause them to be unsuitable as warning signals. However, it was possible that the qualitative contrast between the tone and white noise accounted for the difference. Therefore, the procedure was altered so that a $500-\mathrm{Hz}$ tone and a $1000-\mathrm{Hz}$ tone were the contrasting stimuli. Although all subjects had performed at near-perfect avoidance rates in the presence of white noise, at the time no qualitatively similar auditory stimulus was readily available to juxtapose with white noise. Thus, two frequencies of tone were judged to be the best solution.

The shift in procedure so that each component was differentiated by a unique frequency of tone was at first somewhat successful. For 2 of the 4 rats used in this stage of the study, the $500-\mathrm{Hz}$ and $1000-\mathrm{Hz}$ tones produced similar levels of proficiency. This was judged to be satisfactory for the purposes of the study, and these 2 rats were subjected to the experiment's first condition - a control that compared resistance to extinction in two warning stimuli of equal duration (29 s). Once they met the stability criterion in baseline for both avoidance proficiency and overall response rate, they were given 5 consecutive sessions of extinction (i.e., warning signals were presented, but shocks were omitted from the Sidman schedules). Extinction response rates were calculated as a proportion of baseline response rates.

It had been anticipated that full extinction of either component's response would take multiple sessions. After only one session, however, both rats were emitting almost zero responses in either component. The same held true when the rats were advanced to the second condition, which compared a 20-s signal to a 29-s signal. At that point, a frequency distribution analysis of IRTs was conducted to assess whether the rats responded differentially in the two components. For free-operant avoidance schedules, it is typical for rats to respond when the warning signal comes on (Sidman, 1955). The IRT analysis in the present research showed, contrary to expectations, that the rats were responding in an identical manner across components. Moreover, a frequency distribution of those IRTs showed that the rats' responses tended to be evenly distributed across the RS interval. This was more consistent with how rats respond under free-operant avoidance schedules that feature no warning signal at all (Sidman, 1954; Sidman, 1955). Therefore, the tones were not controlling behavior. 
It was clear that tones-whether $500 \mathrm{~Hz}$ or $1000 \mathrm{~Hz}$-were unsuitable as warning signals, and another pair of signals would have to be presented. In the first phase of the research, white noise had clearly established strong levels of avoidance proficiency for 3 of 4 rats. At the time, no additional warning signal was available that was qualitatively similar to white noise yet different enough for rats to discriminate. Since these first control experiments, however, an appropriate contrasting stimulus to white noise had been found in the form of rapid (32-Hz) click noises, which has previously been demonstrated to function as a warning signal in free-operant avoidance schedules (Weiss \& Schindler, 1981). In the main procedure about to be described, white noise and 32-Hz clicks were used in the two components.

Additionally, the extinction tests were discarded from the overall procedure, and the study proceeded directly to the conditioned punishment tests mentioned earlier. The extinction tests were not judged to be the critical manipulation of the experiment because the assessment of response strength in the presence of a warning signal did not separate that signal's discriminative and aversive functions. In the conditioned punishment tests, a baseline phase would consist of a two-component multiple schedule with different warning signal durations (29s and $5 \mathrm{~s}$ ) in each component. Following this would be a condition in which the 5-s signal would be presented briefly (0.5 s) after each response in the component with the 29-s signal. If the signal's aversive function were stronger than its discriminative function, then one would predict a suppression of responding in the 29-s Signal component. An account that emphasizes the signal's discriminative function, on the other hand, would predict either no change or an increase in responding in the 29-s Signal component.

\section{Procedure}

Preliminary training. Two rats (C4, and $\mathrm{C} 5)$ required preliminary training to shape avoidance. The other 3 rats that participated in the main study (C1, C2, and C3) had previously been trained to avoid shock in the course of the exploratory procedures described above, using a strategy similar to the one described here for C4 and C5.

Using a shaping procedure described by Baron (1991, p. 181-182), the rats first were trained to postpone shock by pressing the right lever. The houselight and the right cue light were illuminated for the entire duration of the session, and they were deactivated when the session ended. Sessions lasted 60 min. Initially, RS intervals were $60 \mathrm{~s}$, but across sessions this value gradually was reduced to $30 \mathrm{~s}$. The SS intervals were $5 \mathrm{~s}$. White noise served as a warning signal 
for Rats C4 and C5, and 32-Hz clicks served for Rats C1, C2, and C3. Warning signals were terminated only when the rat pressed the lever, and the clicker operated following each response. At the beginning of preliminary training, the warning signal came on $3 \mathrm{~s}$ after each response, and this interval was gradually reduced to $1 \mathrm{~s}$ across sessions. Preliminary training with one warning signal type proceeded until rats avoided at least $75 \%$ of the shocks scheduled by the RS $30 \mathrm{~s}$ timer in an entire single session. Once this criterion was met, the procedure was repeated with the other warning signal. Once the rats were avoiding at least $75 \%$ of the RS shocks scheduled with the second warning signal, rats were introduced to the baseline condition of the main procedure.

Design. All 5 rats that served in the punishment study experienced two conditions: baseline and conditioned punishment. One rat (C5) was subjected to a third condition, sham punishment. For Rats C1, C2, and C3, baseline and punishment conditions were alternated in an ABAB design. For Rat C4, baseline and conditioned punishment were arranged in an ABA design, with only a single presentation of the conditioned punishment condition. Rat C5 was presented with alternations of baseline and conditioned punishment, followed by alternations of baseline and sham punishment (ABABCACA design). The conditions in which each rat served, and the number of sessions that each rat served for each condition is shown in Table 1 . The details of each condition are described in the sections that follow.

Table 1

Conditions in which each rat served, and number of sessions in each condition. "BL," "PUN," and "ShamPUN" stand for "baseline," "punishment," and "sham punishment" conditions, respectively. The numbers beside these abbreviations refer to replications of each condition (e.g., "BL 2" stands for the second baseline).

\begin{tabular}{lcccccccc}
\hline & & & & \multicolumn{3}{c}{ Sham } & \multicolumn{3}{c}{ Sham } \\
Rat & BL 1 & PUN 1 & BL 2 & PUN 2 & PUN 1 & BL 3 & PUN 2 & BL 4 \\
\hline \hline C1 & 11 & 12 & 23 & 10 & -- & -- & -- & -- \\
C2 & 14 & 15 & 10 & 14 & -- & -- & -- & -- \\
C3 & 10 & 21 & 16 & 34 & -- & -- & -- & -- \\
C4 & 23 & 14 & 19 & -- & -- & -- & -- & -- \\
C5 & 10 & 10 & 12 & 10 & 12 & 11 & 13 & 11 \\
\hline
\end{tabular}


Sessions under each condition continued until avoidance proficiency and response rate measures were stable for 10 consecutive sessions. Stability was judged according to two criteria: (1) there was no visible upward or downward trend in the data, and (2) the difference between the means of the first 5 sessions and the second 5 sessions did not exceed $15 \%$ of the grand mean. The number of sessions rats required to meet the stability criterion under each condition is listed in Table 1. Sessions were conducted 6 to 7 days per week.

Baseline. The baseline condition was a two-component multiple schedule with freeoperant avoidance in either component. For each component, the RS intervals were $30 \mathrm{~s}$, and the SS intervals were $5 \mathrm{~s}$. In the 29-s-Signal component, the warning signal appeared $29 \mathrm{~s}$ before scheduled RS shocks. In the 5-s-Signal component, the signal appeared 5 s before RS shocks. In both components, the warning signal remained on during the SS interval and was terminated following a response on the right lever. A response also operated the clicker module. For Rats C1 and C3, the 29-s warning signal was a 32-Hz click (82 dB) and the 5-s signal was white noise (82 $\mathrm{dB})$. For Rats C2, C4, and C5 this arrangement was counterbalanced. Components lasted 10 min and were separated by 30-s intercomponent intervals. Sessions consisted of 7 presentations of each component, in strict alternation, and lasted approximately $2.5 \mathrm{hr}$.

Conditioned punishment. The arrangements described for baseline conditions were identical for conditioned punishment sessions, except for the addition of a putative conditioned punisher in the 29-s-Signal component. Whenever a response was emitted in the 29-s-Signal component, the warning signal terminated and the clicker module operated as before, but there was also a brief (0.5 s) presentation of the warning signal that was used in the 5-s-Signal component.

Sham punishment. In sham punishment, the conditions were similar to those described for conditioned punishment. The difference was that instead of briefly presenting the 5-s warning signal following responses emitted in the 29-s-Signal component, a 1000-Hz tone was presented for 0.5 s after each 29-s-Signal response.

\section{Results}

All the results are based on the last 10 stable sessions from each condition.

Table 2 shows the rats' mean percentage of RS shocks avoided in each condition. In each pair of numbers, the first value in bold signifies proficiency in the 29-s-Signal component, and the second signifies proficiency in the 5-s-Signal component. The values in parentheses are the 
standard deviations. "BL," "PUN," and "ShamPUN" stand for "baseline," "punishment," and "sham punishment" conditions, respectively; and the numbers beside these abbreviations refer to replications of each condition (e.g., "BL 2" stands for the second baseline). Throughout the study, Rats C1, C3, and C5 were less proficient in the 29-s-Signal component than in the 5-sSignal component. For Rat C4, the tendency is reversed, with a more proficient performance in the component with the 29-s signal. Rat C2's proficiency remained approximately equal across components in every condition. Across conditions, proficiency did not change systematically for Rats C1, C2, and C3. However, for Rat C4 each successive condition resulted in a decline in proficiency under the 5-s-Signal component; and Rat C5's proficiency in the 29-s-Signal component decreased slightly after transitioning to the third baseline but remained at the same level for the remaining two conditions.

Table 2

Percentage of RS shocks avoided in each condition. "BL," "PUN," and "ShamPUN" stand for "baseline," "punishment," and "sham punishment" conditions, respectively. The numbers beside these abbreviations refer to replications of each condition (e.g., "BL 2" stands for the second baseline).Percentages are based on shocks programmed by the RS interval, and represent means of the last 10 sessions in each condition. In each quartet of numbers, the first bold value is from the 29-s Signal component, and the second bold value is from the 5-s Signal component. The values in parentheses are the standard deviations for each of the means.

\begin{tabular}{|c|c|c|c|c|c|c|c|c|}
\hline Rat & BL 1 & PUN 1 & BL 2 & PUN 2 & $\begin{array}{l}\text { Sham } \\
\text { PUN } 1\end{array}$ & BL 3 & $\begin{array}{l}\text { Sham } \\
\text { PUN } 2\end{array}$ & BL 4 \\
\hline C1 & $\begin{array}{c}54 / 99 \\
(6) /(1)\end{array}$ & $\begin{array}{l}\mathbf{4 0} / \mathbf{9 9} \\
(4) /(1)\end{array}$ & $\begin{array}{l}\mathbf{4 4} / \mathbf{9 9} \\
(6) /(1)\end{array}$ & $\begin{array}{l}\mathbf{4 6} / \mathbf{9 9} \\
(8) /(1)\end{array}$ & -- / -- & -- / -- & -- / -- & -- / -- \\
\hline C2 & $\begin{array}{l}72 \text { / } 68 \\
(8) /(8)\end{array}$ & $\begin{array}{l}79 \text { / } 81 \\
(4) /(5)\end{array}$ & $\begin{array}{l}75 / 74 \\
(5) /(5)\end{array}$ & $\begin{array}{l}78 \text { / } 72 \\
(5) /(8)\end{array}$ & -- / -- & $--/$-- & -- / -- & -- / -- \\
\hline C3 & $\begin{array}{l}47 \text { / } 90 \\
(8) /(6)\end{array}$ & $\begin{array}{c}\mathbf{5 4} / \mathbf{9 1} \\
(5) /(3)\end{array}$ & $\begin{array}{l}\mathbf{5 7} / 81 \\
(8) /(5)\end{array}$ & $\begin{array}{c}59 \text { / } 89 \\
(12) /(4)\end{array}$ & -- / -- & $--/$-- & $--/$-- & -- / -- \\
\hline C4 & $\begin{array}{l}100 / 88 \\
(1) /(2)\end{array}$ & $\begin{array}{l}\mathbf{1 0 0} / \mathbf{7 8} \\
(1) /(11)\end{array}$ & $\begin{array}{r}100 / 62 \\
(0) /(8)\end{array}$ & -- / -- & -- / -- & -- / -- & -- / -- & -- / -- \\
\hline C5 & $\begin{array}{l}86 / 92 \\
(6) /(10)\end{array}$ & $\begin{array}{c}83 / 95 \\
(3) /(2)\end{array}$ & $\begin{array}{c}\mathbf{8 4} / \mathbf{9 7} \\
(11) /(1)\end{array}$ & $\begin{array}{l}74 / 96 \\
(7) /(3)\end{array}$ & $\begin{array}{l}82 / 97 \\
(4) /(2)\end{array}$ & $\begin{array}{l}70 / 96 \\
(6) /(3)\end{array}$ & $\begin{array}{c}\mathbf{6 9} / \mathbf{8 9} \\
(7) /(5)\end{array}$ & $\begin{array}{c}73 / 92 \\
(6) /(3)\end{array}$ \\
\hline
\end{tabular}


Figure 1 shows a set of frequency distributions of IRTs in each component of the first two baseline conditions, and of the average of those baselines. The IRTs are sorted into 0.5-s bins. IRTs from the 29-s-Signal component are shown with dashed lines, IRTs from the 5-sSignal component with solid lines. For each rat, and in both baselines, the distributions differ across components. In the 29-s-Signal component, rats tended either to respond within a few seconds of the appearance of the warning signal at $1 \mathrm{~s}$, or immediately following the delivery of an RS shock at $30 \mathrm{~s}$. In the 5-s component, the mode of every rat's distribution occurs within a few seconds of the onset of that component's signal at $25 \mathrm{~s}$.

Figure 2 shows the mean overall response rates in each component in each condition. Error bars represent one standard deviation. Within each condition, rates were higher in the 29-sSignal component than in the 5-s-Signal component for every rat except C2. For Rat C2, response rates were approximately equal across components. In the 29-s-Signal component, there were no systematic differences across conditions for Rats C1, C2, or C4. Rat C1's rates in the 29-s-Signal component decreased following the transition from the initial baseline (BL) to conditioned punishment (PUN), but rates did not return to their previous levels in the subsequent return to baseline. For Rats C2 and C4, no changes in rate were apparent in the 29-s-Signal component at all. For Rat C3, introducing the putative conditioned punisher in the 29-s-Signal component resulted in modest increases in rate relative to baseline performance in that component. For Rat C5 response rates in the 29-s-Signal component were lower in the conditioned punishment condition than in the baseline. When an arbitrary stimulus, a tone, was presented in place of the conditioned punisher (sham punishment, or ShamPUN), Rat C5's response rates in the 29-s-Signal component rose to approximate original baseline rates. However, subsequent presentations of the baseline condition resulted in rates that were much lower than those in the original baseline, and the response rates obtained in a repetition of the sham punishment were lower than rates obtained in both the first sham punishment and in the last two repetitions of the baseline condition. For all rats, there were no systematic changes in response rate in the 5-s-Signal component, except for Rat C5, for which there was a modest decrease in rate across all conditions, from first baseline to last.

A cross-condition comparison of IRT distributions for Rats C1, C2, C3, and C4 are shown in Figures 3, 4, 5, and 6, respectively. In each panel of each figure, the solid line represents data from one condition, and the dashed line represents the condition that followed. 
Baseline 1
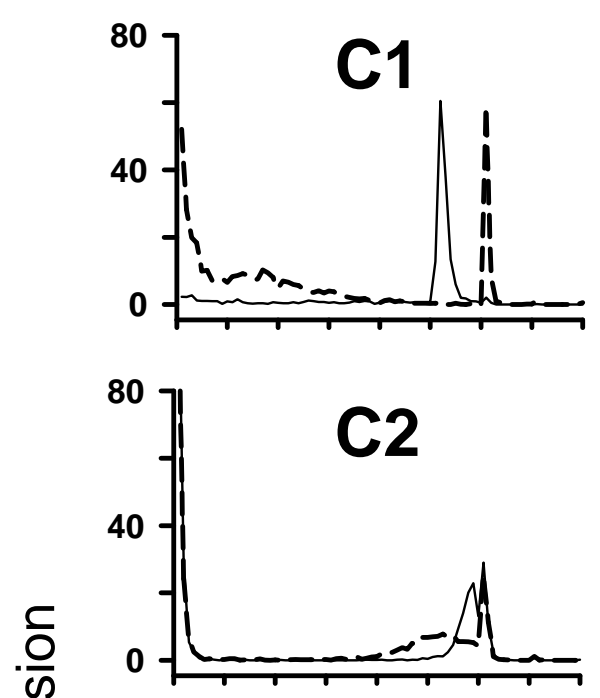

()

(1)

ปั

요

ज)

등

$\frac{8}{n}$

$\stackrel{1}{\alpha}$
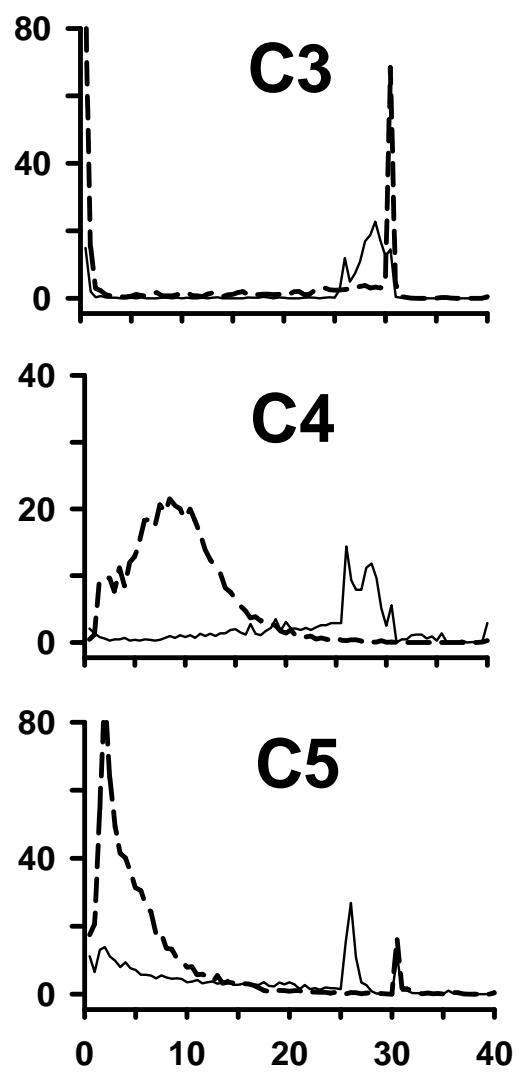

Baseline 2
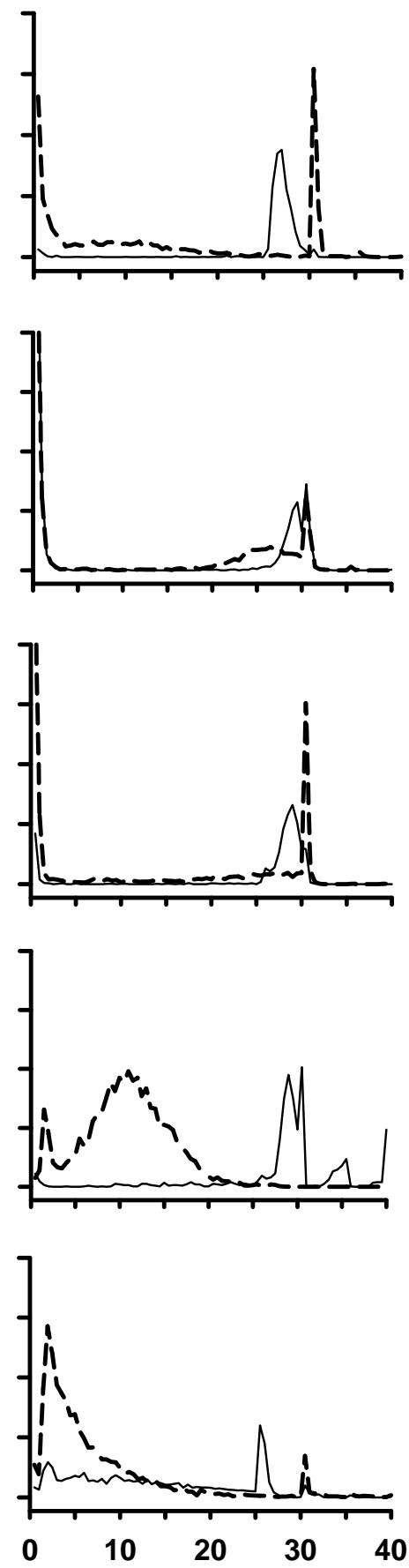

Combined Baseline
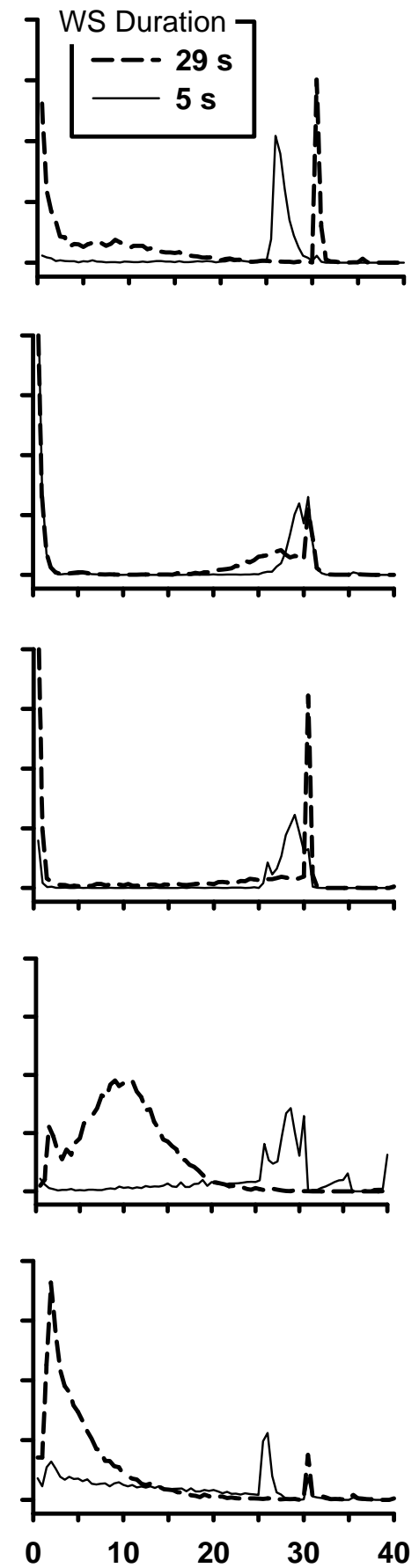

Interresponse time (s)

Fig. 1. Frequency distributions of interresponse times in each component of the first two baseline conditions (left and middle columns), and of the average of those baselines (right column). Values plotted are means of the last 10 sessions of each condition. The IRTs are sorted into 0.5 -s bins. The final bin (40 s, on the x-axis) represents all IRTs $40 \mathrm{~s}$ and longer. 


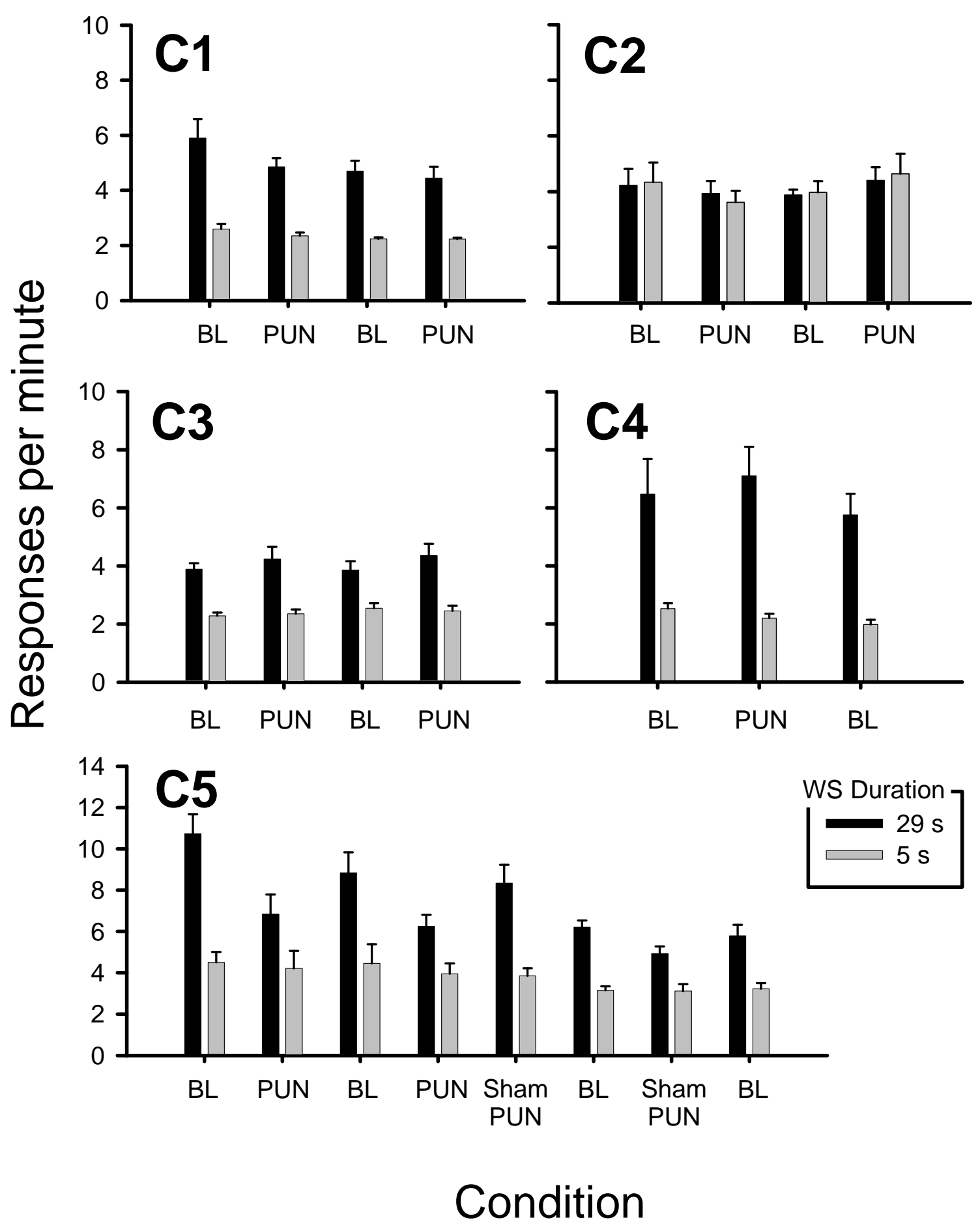

Fig. 2. Mean response rates in each component of the multiple schedule, measured across the last 10 sessions of each condition. Error bars represent one standard deviation. "BL" identifies baseline conditions, "PUN" identifies punishment, and "ShamPUN" identifies sham punishment. 


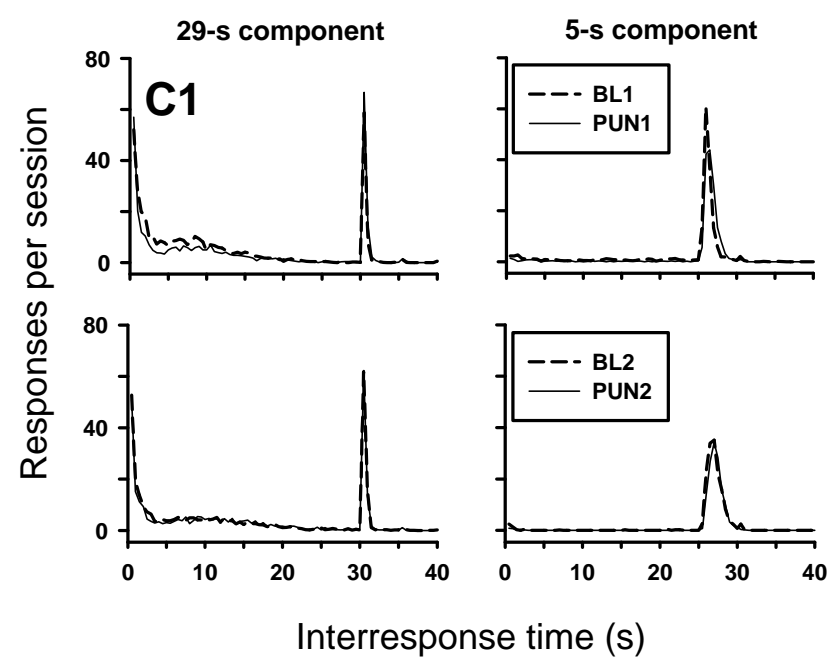

Fig. 3. Rat C1's interresponse time distributions in several pairs of sequentially presented conditions. Data from the 29-s-Signal component of the multiple schedule appears in the left column, and data from the 5-s-Signal component appears in the right column. In each panel, the dashed lines show the preceding condition, and the solid line shows the condition to which there is a transition in the procedure. Values plotted are means of the last 10 sessions of each condition. The IRTs are sorted into 0.5-s bins. The final bin (40 s, on the x-axis) represents all IRTs $40 \mathrm{~s}$ and longer.

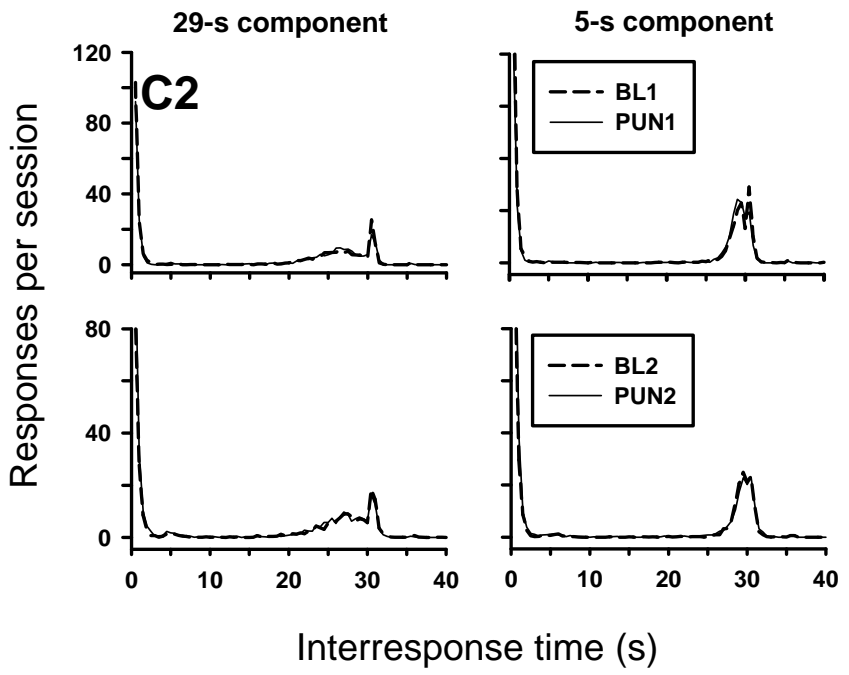

Fig. 4. Rat C2's interresponse time distributions in several pairs of sequentially presented conditions. Data from the 29-s-Signal component of the multiple schedule appears in the left column, and data from the 5-s-Signal component appears in the right column. In each panel, the dashed lines show the preceding condition, and the solid line shows the condition to which there is a transition in the procedure. Values plotted are means of the last 10 sessions of each condition. The IRTs are sorted into 0.5-s bins. The final bin (40 s, on the x-axis) represents all IRTs $40 \mathrm{~s}$ and longer. 


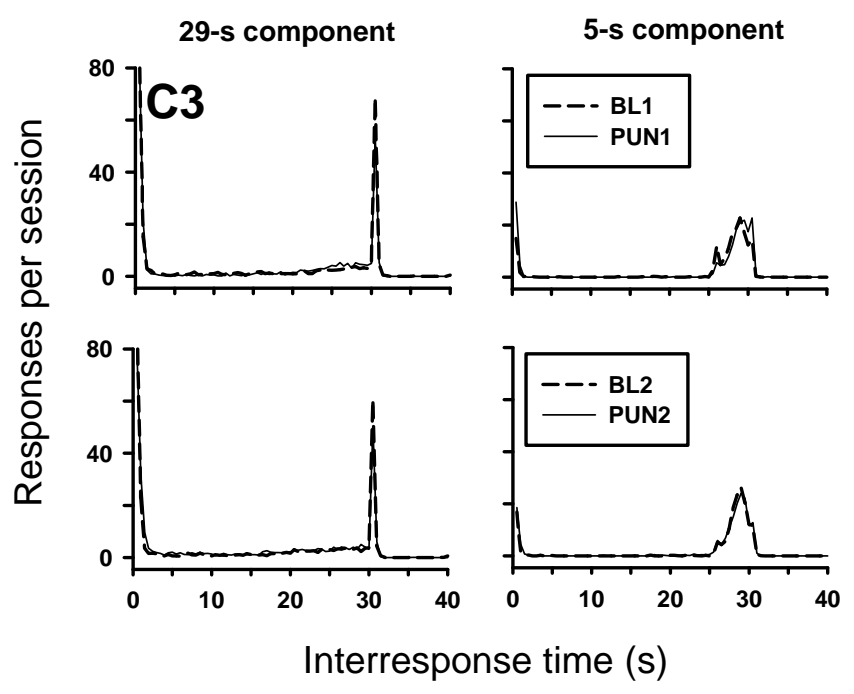

Fig. 5. Rat C3's interresponse time distributions in several pairs of sequentially presented conditions. Data from the 29-s-Signal component of the multiple schedule appears in the left column, and data from the 5-s-Signal component appears in the right column. In each panel, the dashed lines show the preceding condition, and the solid line shows the condition to which there is a transition in the procedure. Values plotted are means of the last 10 sessions of each condition. The IRTs are sorted into 0.5 -s bins. The final bin ( $40 \mathrm{~s}$, on the $\mathrm{x}$-axis) represents all IRTs $40 \mathrm{~s}$ and longer.

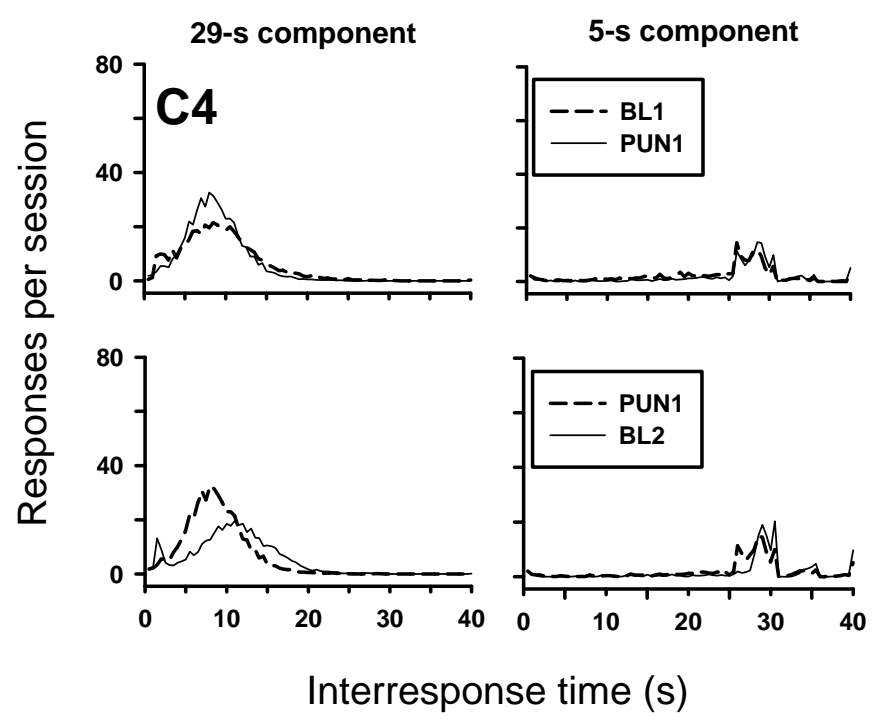

Fig. 6. Rat C4's interresponse time distributions in several pairs of sequentially presented conditions. Data from the 29-s-Signal component of the multiple schedule appears in the left column, and data from the 5-s-Signal component appears in the right column. In each panel, the dashed lines show the preceding condition, and the solid line shows the condition to which there is a transition in the procedure. Values plotted are means of the last 10 sessions of each condition. The IRTs are sorted into 0.5 -s bins. The final bin ( $40 \mathrm{~s}$, on the $\mathrm{x}$-axis) represents all IRTs $40 \mathrm{~s}$ and longer. 
So, for example, in the uppermost-left panel of Figure 3, Rat C1's first baseline condition (BL1, solid line) is followed by his first conditioned punishment condition (PUN1, dashed line). For Rats C1, C2, and C3 (Figures 3, 4, and 5) the first and second rows of panels show the first transition from baseline to conditioned punishment (BL1 to PUN1) and the replication (BL2 to PUN2), respectively. For Rat C4 (Figure 6), the same panels show the transition from baseline to conditioned punishment (BL1 to PUN1) and from conditioned punishment back to baseline (PUN1 to BL2). In the conditioned punishment procedure, the warning signal from the 5-sSignal component was presented briefly after every response in the 29-s-Signal component. Distributions of IRTs in the 29-s-Signal component are shown for Rats C1, C2, C3, and C4 in the left-side panels of Figures 3, 4, 5, and 6. For Rats C1, C2, and C3 neither of the transitions from baseline to the conditioned punishment condition resulted in any significant reduction in the number of responses that occurred early in the 29-s-Signal component's RS interval. For Rat C4, there was a slight increase in the number of short IRTs in the 29-s-Signal component when the transition was made from baseline to conditioned punishment, and then a decrease in short IRTs in the return to baseline. Distributions of IRTs in the 5-s-Signal component are shown in the right-side panels of Figures 3, 4, 5, and 6. None of the changes of condition resulted in any differences in the IRT distributions in this component for Rats C1, C2, C3, or C4. This was as expected, because all of the manipulations in the study involved changes in the structure of the 29-s-Signal component only.

Rat C5's IRT distributions are shown in Figure 7. As in the other distributions, the solid line represents data from one condition, and the dashed line represents the condition that follows. Distributions of Rat C5's IRTs in the 29-s-Signal component are shown in the left-side panels. The first and second panels on the left show the first transition from baseline to conditioned punishment (BL1 to PUN1) and the replication (BL2 to PUN2), respectively. Introducing the putative conditioned punisher in the 29-s-Signal component resulted in fewer responses during the early portion of the RS interval, suggesting that the stimulus had an aversive function that suppressed responding. The IRT distributions for Rat C5's transition from conditioned punishment to the sham punishment condition (PUN2 to ShamPUN1) is shown for the 29-sSignal component in the third row on the left of Figure 3. In sham punishment, every response in the 29-s-Signal component was followed by a 0.5-s presentation of a tone. Relative to conditioned punishment, the number of short IRTs in that component increased following the 
introduction of sham punishment. The mode of the sham punishment distribution does not assume the same intensity as that of the first baseline, but it does approximate the intensity of the second baseline, suggesting that sham punishment was functionally equivalent to baseline conditions. When the transition was made to a third baseline (ShamPUN1 to BL3, fourth row of Figure 3), the 29-s-Signal component's distributions showed a decrease in short IRTs. Further flattening of the distribution occurred with the change back to sham punishment conditions (BL3 to ShamPUN2, fifth row). Distributions of Rat C5's IRTs in the 5-s-Signal component are shown in the right-side panels in Figure 3. None of the changes of condition resulted in any changes in the IRT distribution in this component.

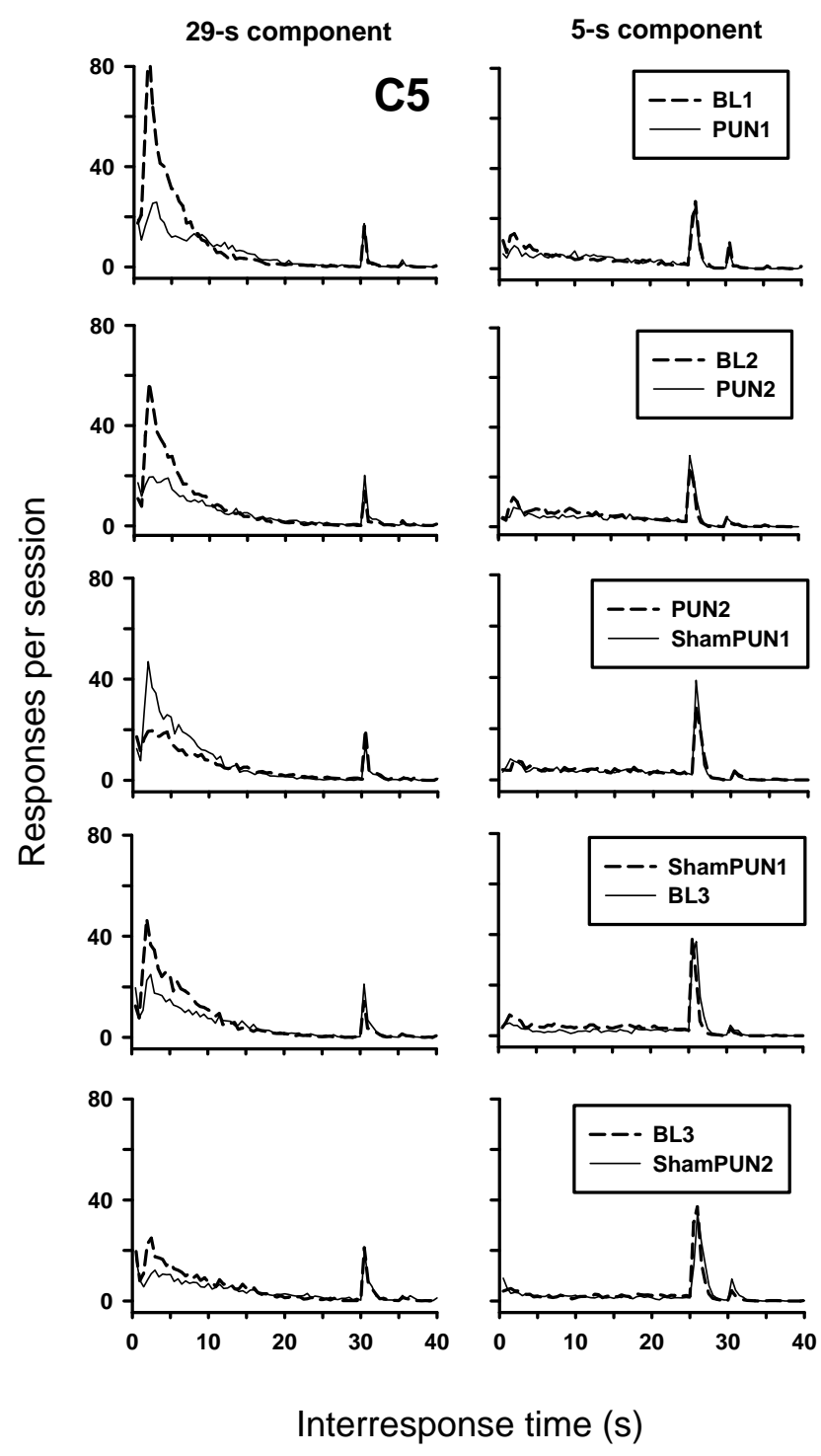

Figure 7. Rat C5's interresponse time distributions in several pairs of sequentially presented conditions. Data from the 29-sSignal component of the multiple schedule appears in the left column, and data from the 5-s-Signal component appears in the right column. In each panel, the dashed lines show the preceding condition, and the solid line shows the condition to which there is a transition in the procedure. Values plotted are means of the last 10 sessions of each condition. The IRTs are sorted into 0.5-s bins. The final bin (40 s, on the $\mathrm{x}$-axis) represents all IRTs $40 \mathrm{~s}$ and longer. 


\section{Discussion}

In the present study, rats responded in a two-component multiple schedule of free-operant shock avoidance. A distinct warning signal was presented in each component, and signals differed primarily in terms of their durations (29 s versus $5 \mathrm{~s}$ ). When, in a conditioned punishment phase, the 5-s signal was presented briefly (0.5 s) following responses in the 29-sSignal component, there was little or no effect on the response rates and IRT distributions in the 29-s-Signal component for four of the five rats (C1, C2, C3, and C4). Relative to baseline, the fifth rat (C5) showed lower response rates and fewer short IRTs in the 29-s-Signal component in conditioned punishment. When Rat C5 was introduced to a sham punishment condition, his response rates and IRT distributions in the 29-s-Signal component approximated baseline results. However, subsequent attempts with this rat to replicate baseline and sham punishment conditions were a failure. Taken together, the results show no consistent suppression of responding when a warning signal is presented contingent upon a response. The sole exception is Rat C5, for whom the results are difficult to interpret, given that presenting an arbitrary stimulus contingent on responding had inconsistent effects.

Given the manipulations in this study, the most straightforward prediction of the twofactor theory of avoidance would have been that, in conditioned punishment, the putative conditioned punisher would have acquired an aversive function through its correlation with shock in the 5-s-Signal component, and this aversive function would result in the suppression of responding when the stimulus was presented contingent upon responses in the 29-s-Signal component. Meanwhile, the most straightforward prediction of the one-factor theory would have been that the discriminative function of the 5-s signal would have transferred when that signal was produced by a response in the 29-s-Signal component. That is, in the presence of a stimulus that is otherwise correlated with a relatively efficient interval in which to respond in the 5-sSignal component would have been likely to induce a response at the beginning of the RS interval of the 29-s-Signal component, and overall response rates in the latter component would have increased. Yet neither theory's predictions were consistently upheld by the results. An analysis of the IRT distributions for Rat C1, C2, C3, and C4 shows no substantial or consistent increase or decrease in the number of short IRTs. Of those first four rats, three rats $(\mathrm{C} 1, \mathrm{C} 2$, and C3) showed no systematic effect of the conditioned punishment condition on response rates, and Rat C4 displayed only a slight increase in response rates during the 29-s-Signal component with 
the transition to conditioned punishment. Rat (C5) showed a moderate decrease in rates and short IRTs when conditioned punishment was applied, which was consistent with two-factor theory. When Rat C5 was subjected to sham punishment, response rates in the 29-s-Signal component were comparable to earlier baselines, which was also consistent with a two-factor-theory interpretation. However, subsequent attempts to replicate the sham punishment results were unsuccessful.

\section{Possible Interpretations}

It should be noted that the failures to replicate baseline and sham punishment with Rat C5 were coincident with a relatively low proficiency in the 29-s-Signal component: Compared to his performance in preceding conditions, Rat C5 avoided a mean of 9 percent to 13 percent fewer RS shocks in the third and fourth baseline conditions and the second sham punishment condition. Whether lower proficiency resulted in lower response rates, or vice versa, or both were a direct result of transitioning from the first sham punishment condition, is impossible to interpret with certainty in the absence of further experimental manipulations. However, one possible explanation for the decrease in Rat C5's proficiency in the later conditions is the emergence of a contrast effect. It may have been that the sham punisher, because of its negative correlation with shock, functioned as a safety signal that was more salient than the mere offset of the warning signal under baseline conditions. Therefore, when the sham punisher was removed in the transition from sham punishment to baseline, the onset of the warning signal was less discriminable. Subsequent repetitions of sham punishment and baseline simply might have built on the permanent effects of that initial shift. The plausibility of this explanation is at least partially supported by the observation that Rat C5 emitted fewer IRTs that approximated the offset time of the warning signal (see Figure 1, fourth panel on the left). However, it begs the question why the conditioned punisher, which was also correlated negatively with shock in the 29-s-Signal component, did not also produce a contrast effect in this manner.

The latter criticism points to the fact that the two-factor theory offers an alternative prediction of the present procedure that could provide some explanation for the results of the other four rats. In the conditioned punishment phase, the brief stimulus presented after every 29s-Signal response would acquire the function of a safety signal due to its negative correlation with shock. This safety function would work against the aversive function that the stimulus acquires through its positive correlation with shock in the 5-s-Signal component, and the net 
effect on responding in either component is approximately zero. While this might explain the null or insignificant results with Rats C1, C2, C3 and perhaps even C4, it also illustrates the twofactor theory's inability to offer an exclusive prediction of the results of the present procedure. If a wide range of outcomes are plausible within the theory's framework, then in hindsight the procedure was not effective as a test that would confirm or disconfirm the two-factor theory.

\section{Future Directions}

A possibility for future research that might circumvent many of the interpretive confounds discussed in the preceding paragraphs is to repeat the procedure in the present study, but with one major change: in the multiple schedule one component would be a variable-interval (VI) schedule of positive reinforcement. In a VI schedule, the first response after a varying, random length of time is reinforced; and the typical effect is that subjects respond at a constant, steady rate (Ferster \& Skinner, 1957). The other component in the hypothetical multiple schedule would remain signaled free-operant avoidance, and in a "conditioned punishment" phase its warning signal would be presented contingent on responses in the VI component. Because the interreinforcement interval in a VI schedule is variable, response-contingent conditioned punishers would not reliably predict the time to next reinforcement (as the conditioned punishers did in the present study). Moreover, if each component were assigned to a separate operandum, the discriminative role of the warning signal could be assessed directly by monitoring whether subjects respond to the avoidance operandum when the conditioned punisher is delivered in the reinforcement component.

The analysis of free-operant avoidance behavior continues to face interpretive challenges in light of the difficulties of arranging a procedure that successfully rules out either a one-factoror a two-factor-theory explanation. The present study represents an attempt to construct such a procedure. The attempt ultimately showed only limited success, but it is possible that a variation on the procedure-with, for example, a positive-reinforcement behavior as the object of conditioned punishment—may provide a solution. 


\section{References}

Baron, A. (1991). Avoidance and punishment. In I. H. Iversen \& K. A. Lattal (Eds.), Experimental Analysis of Behavior (Part 1, pp. 173-217). Amsterdam: Elsevier.

De Moraes, A. B. A., \& Todorov, J. C. (1977). Signalled free-operant avoidance of shock by pigeons pecking a key. JEAB, 27, 281-291.

Dinsmoor, J. A. (1954). Punishment: I. The avoidance hypothesis. Psychological Review, 61, 3446.

Dinsmoor, J. A. (1977). Escape, avoidance, punishment: Where do we stand? JEAB, 28, 83-95.

Dinsmoor, J. A. (2001). Stimuli inevitably generated by behavior that avoids electric shock are inherently reinforcing. JEAB, 75, 311-333.

Dinsmoor, J. A., \& Sears, G. W. (1973). Control of avoidance by a response-produced stimulus. Learning and Motivation, 4, 284-293.

Ferster, C. B., \& Skinner, B. F. (1957). Schedules of reinforcement. Acton, MA: Copley Publishing Group.

Frieman, J. P., Warner, J., \& Riccio, D. C. (1970). Age differences in conditioning and generalization of fear in young and adult rats. Developmental Psychology, 3, 119-123.

Herrnstein, R. J. (1969). Method and theory in the study of avoidance. Psychological Review, 76, 49-69.

Herrnstein, R. J., \& Hineline, P. N. (1966). Negative reinforcement as shock-frequency reduction. JEAB, 9, 421-430.

Hineline, P. N. (1977). Negative reinforcement and avoidance. In W. K. Honig \& J. E. R. Staddon (Eds.), Handbook of Operant Behavior (pp. 364-414). Englewood Cliffs, NJ: Prentice-Hall.

Hineline, P. N. (1981). The several roles of negative reinforcement. In P. Harzem \& Zeiler (Eds.), Advances in analysis of behavior: Vol. 2. Predictability, correlation, and contiguity (pp. 203-246). Cichester, England: Wiley.

Hyman, A. (1969). Two temporal parameters of free operant discriminated avoidance in the rhesus monkey. Journal JEAB, 12, 641-648.

Mikorski, J. (1993). Behavior maintained by timeout from signaled avoidance: Effects of signal duration. Unpublished masters thesis, West Virginia University, Morgantown. 
Mowrer, O. H. (1939). A stimulus-response analysis of anxiety and its role as a reinforcing agent. Psychological Review, 46, 553-565.

Mowrer, O. H. (1947). On the dual nature of learning - a reinterpretation of "conditioning” and “problem-solving.” Harvard Educational Review, 17, 102-148.

Mowrer, O. H., \& Lamoreaux, R. R. (1942). Avoidance conditioning and signal duration-a study of secondary motivation and reward. Psychological Monographs, 54, No. 5. (Whole No. 247).

Nevin, J. A. (1974). Response strength in multiple schedules. JEAB, 21, 389-408.

Nevin, J. A. (1979). Reinforcement schedules and response strength. In M. D. Zeiler \& P. Harzem (Eds.), Reinforcement and the Organization of Behaviour (pp. 117-158). New York: Wiley.

Schoenfeld, W. N. (1950). An experimental approach to anxiety, escape, and avoidance behavior. In P. H. Hoch \& J. Zubin (Eds.), Anxiety (pp. 70-99). New York: Grune \& Stratton.

Sidman, M. (1953a). Avoidance conditioning with brief shock and no exteroceptive warning signal. Science, 118, 157-158.

Sidman, M. (1953b). Two temporal parameters of the maintenance of avoidance behavior by the white rat. Journal of Comparative and Physiological Psychology, 46, 253-261.

Sidman, M. (1954). The temporal distribution of avoidance responses. Journal of Comparative and Physiological Psychology, 47, 399-402.

Sidman, M. (1955). Some properties of the warning stimulus in avoidance behavior. Journal of Comparative and Physiological Psychology, 48, 444-450.

Sidman, M. (1957). Conditioned reinforcing and aversive stimuli in an avoidance situation. Transactions of the New York Academy of Science, 19, 534-544.

Sidman, M. (1966). Avoidance behavior. In W. K. Honig (Ed.), Operant behavior: Areas of research and application (pp. 448-498). New York: Appleton-Century-Crofts.

Sidman, M. (2001). Safe periods both explain and need explaining. JEAB, 75, 335-365.

Sidman, M., \& Boren, J. J. (1957a). A comparison of two types of warning stimulus. Journal of Comparative and Physiological Psychology, 50, 282-287.

Sidman, M., \& Boren, J. J. (1957b). The relative aversiveness of warning signal and shock in an avoidance situation. The Journal of Abnormal and Social Psychology, 55, 339-344. 
Skinner, B. F. (1953). Science and human behavior. New York: Macmillan.

Ulrich, R. E., Holz, W. C., \& Azrin, N. H. (1964). Stimulus control of avoidance behavior. Journal of the Experimental Analysis of Behavior, 7, 129-133.

Weiss, S. J., \& Schindler, C. W. (1981). Generalization peak shift in rats under conditions of positive reinforcement and avoidance. $J E A B, 35,135-145$.

Wertheim, G. A. (1965). Behavioral contrast during multiple avoidance schedules. JEAB, 8, 269278. 


\section{Bobby E. Phillips}

53 Campus Dr. | 2106 Life Sciences Building | Morgantown, WV 26506 | (256)-572-6721 |

Bobby.Phillips@mail.wvu.edu

\section{Education}

Bachelor of Science, Psychology

The University of Alabama at Birmingham

- Major: Psychology, with Honors in Psychology

- Graduated: May 2008

\section{Honors}

2008 to present. Higher Education Resource Fund (HERF) Award

2004 to 2008. The University of Alabama at Birmingham University Scholars Award

\section{Professional Affiliations}

Society for the Quantitative Analyses of Behavior

Student Member, 2009-present

Association for Behavior Analysis

Student Member, 2009-present

Southeastern Association for Behavior Analysis

Student Member, 2008-2009

\section{Theses}

Phillips, B. (2008). Measurement of natural speech in the life situation - Is it feasible?, Unpublished Honors thesis, The University of Alabama at Birmingham.

\section{Presentations}

Phillips, B. (2010, March). The steep and thorny path to dissociating the reinforcing and discriminative roles of a warning signal in a free-operant avoidance situation. Paper presented at the West Virginia University Department of Psychology Behavior Analysis Weekly Seminar, Morgantown, WV.

Phillips, B. (2009, April). Dissociating the reinforcing and discriminative roles of a warning signal in a free-operant avoidance situation. Paper presented at the West Virginia University Department of Psychology Behavior Analysis Weekly Seminar, Morgantown, WV.

Phillips, B. (2008, April). Measurement of natural speech in the life situation - Is it feasible? Poster presented at the University of Alabama at Birmingham John W. P. Ost Annual Undergraduate Research Competition, Birmingham, AL.

\section{Research Experience}

Undergraduate Research Assistant (Jan. 2007 to May 2008)

The University of Alabama at Birmingham

- Participated in the collection and analysis of speech samples from persons with strokerelated language disabilities in the lab of Dr. Edward Taub.

- Presented research in a public forum at the University of Alabama at Birmingham in partial fulfillment of the requirement for graduation with Honors in Psychology. 
Master's Thesis Research (Aug. 2009 to June 2010)

West Virginia University

- Programmed multiple-schedule, signaled-avoidance procedures in Visual Basic ${ }^{\circledR}$ 2008, as well as programs for related data analysis.

- Presented progress in thesis research at the Behavior Analysis program area's weekly spring Seminar in March 2010.

\section{Teaching Experience}

Graduate Teaching Assistant (Aug. 2008 to present)

West Virginia University

- Course: Behavior Principles Laboratory (Aug. 2008 - May 2009)

- Course: Introduction to Human Development (Aug. 2008 - Dec. 2010)

\section{Professional Conferences Attended}

Society for the Quantitative Analyses of Behavior (May 2010)

Annual Convention

Phoenix, AZ

The Association for Behavior Analysis (May 2010)

Annual Convention

Phoenix, AZ

Southeastern Association for Behavior Analysis (Oct. 2009)

Annual Converence

Wilmington, NC

\section{Skills \& Qualifications}

Research

- Extensive knowledge of SPSSX and SAS statistical programs.

- Participated in the collection and analysis of speech samples from persons with strokerelated language disabilities.

- Collected and analyzed behavioral data of Sprague-Dawley rats

Computer

- Microsoft Office, Internet Explorer.

- Programming ability in Visual Basic ® 2008.

Communication

- Semi-fluent in German and Spanish.

- Presented discussions on research articles in the research lab of Dr. Michael Perone.

\section{References}

Michael Perone, Ph.D.

Professor, West Virginia University

Michael.Perone@mail.wvu.edu 
Edward Taub, Ph.D.

Professor, University of Alabama at Birmingham etaub@uab.edu

Kennon A. Lattal, Ph.D.

Professor, West Virginia University

Andy.Lattal@mail.wvu.edu 